\title{
DESENVOLVIMENTO DE TESTE EM CIRCUITO FECHADO (LCT) PARA FLOTAÇÃO DE MINÉRIO DE FERRO COM BAIXO TEOR ${ }^{\star}$
}

\section{Resumo}

Adriano Santos ${ }^{1}$ Camilo Silva ${ }^{2}$ Kelly Ferreira ${ }^{3}$ Leandro Macie/ ${ }^{4}$

O presente trabalho busca apresentar o desenvolvimento, as diferenças e os resultados dos testes de flotação em bancada em circuito fechado (locked cycle test - LCT), desenvolvidos para avaliar o circuito industrial do projeto Morro do Pilar da Manabi que foi projetado para processar um itabirito com $30 \%$ de teor de ferro. Para buscar a máxima eficiência na recuperação de ferro a rota de processo desenvolvida prevê a flotação em duas estreitas faixas de tamanho: a faixa $-0,15+0,044 \mathrm{~mm}$ será processada em células mecânicas e a fração $-0,044 \mathrm{~mm}$ em colunas de flotação. Por se tratar de um minério de baixo teor, houve a necessidade de desenvolver um teste de bancada, preciso e robusto, para avaliar o desempenho do itabirito no circuito industrial projetado, composto por etapas de flotação rougher, cleaner, recleaner e scavenger. $O$ teste em circuito fechado desenvolvido apresentou excelentes resultados, coerentes com o desempenho de testes piloto contínuos feitos com 0 mesmo itabirito pobre.

Palavras-chave: Flotação; Locked cycle test (LCT).

\section{DEVELOPMENT OF FLOTATION LOCKED CYCLE TEST FOR LOW GRADE IRON ORE}

\section{Abstract}

This study aims to present the development, the differences and the results of the flotation locked cycle test - LCT - developed in order to assess the industrial flowsheet of Morro do Pilar Project, which belongs to Manabi S/A, a Brazilian mining company. The project is designed to produce 25Mtpy processing an Itabirite ore with $30 \%$ iron content. To achieve maximum efficiency in iron recovery, the process flowsheet which has been developed provides flotation in two narrow size ranges: the one $-0.15+0.044 \mathrm{~mm}$ will be processed in mechanical cells and the other $-0.044 \mathrm{~mm}$ fraction in flotation columns. Considering to be a low-grade ore it was necessary to develop a bench scale test with accuracy and robustness to evaluate the ore performance to evaluate the designed industrial circuit, composed by flotation rougher, cleaner, and scavenger recleaner. The locked cycle test developed showed excellent results in line with the performance of continuous pilot tests performed with the same poor itabirite.

Keywords: Flotation; Locked cycle test.

Engo de Minas, MSc, Engenheiro Especialista, Manabi S.A.

Eng ${ }^{\circ}$. de Minas, Gerente Geral de Processos e Tecnologia, Manabi S.A.

Engo Metalurgista, Engenheira de Processos, Manabi S.A.

Engo Metalurgista, Gerente de Processos Minerais, Manabi S.A.

* Contribuição técnica ao $44^{\circ}$ Seminário de Redução de Minério de Ferro e Matérias-primas, 15ํ Simpósio Brasileiro de Minério de Ferro e $2^{\circ}$ Simpósio Brasileiro de Aglomeração de Minério de Ferro, 15 a 18 de setembro de 2014, Belo Horizonte, MG, Brasil. 


\section{INTRODUÇÃO}

A flotação é um processo de separação baseado nas diferenças das características de superfície entre diferentes partículas sólidas. A seletividade do processo de flotação se baseia no fato de que a superfície de diferentes espécies minerais pode apresentar distintos graus de hidrofobicidade. Partículas hidrofóbicas são menos ávidas por água. Os reagentes coletores permitem que os minerais hidrofílicos possam ter sua superfície tornada hidrofóbica através da sua adsorção. Para minérios de ferro a flotação ocorre tipicamente em uma única fração granulométrica $-0,15 \mathrm{~mm}$. O tamanho das partículas para a flotação depende do grau de liberação dos minerais em questão. Alguns autores já mostraram importantes diferenças entre o comportamento na flotação de uma mesma amostra quando classificada e submetida ao processo de concentração em duas frações granulométricas distintas ou quando flotada em uma única fração granulométrica sem essa classificação. Baseando-se nos ganhos atribuídos à flotação em duas frações granulométricas distintas, a Manabi desenvolveu uma rota de processos industrial para o projeto Morro do Pilar, para produção de 25Mtpa de pellet feed, com classificação granulométrica e flotação em células mecânicas para a fração $-0,15+0,044 \mathrm{~mm}$ e flotação em colunas para a fração $-0,044 \mathrm{~mm}$, conforme representado na figura abaixo.

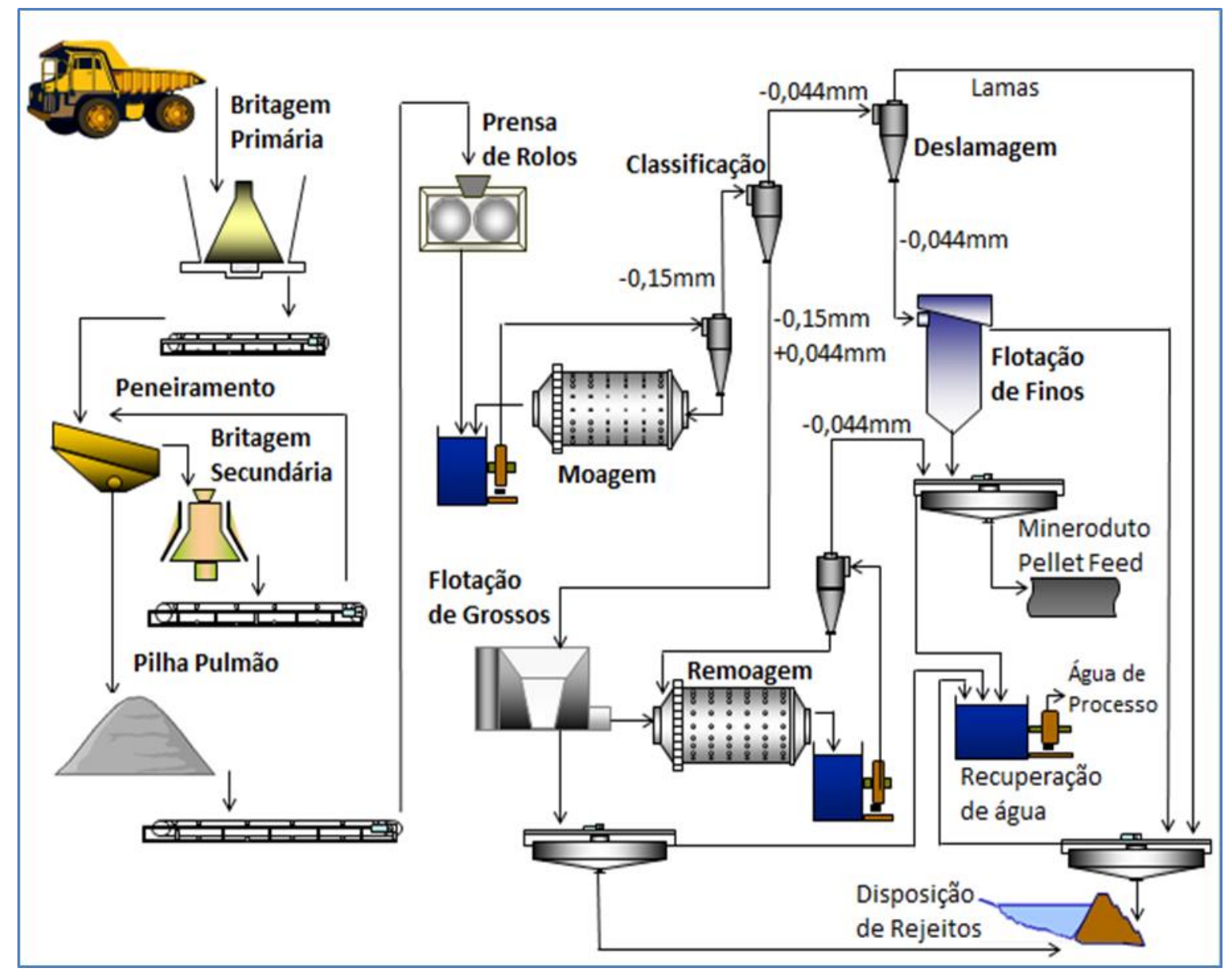

Figura 1: Fluxograma do projeto Morro do Pilar

O presente trabalho foi desenvolvido com amostras de testemunhos de sondagem representativas do depósito de itabiritos do projeto da Manabi.

* Contribuição técnica ao $44^{\circ}$ Seminário de Redução de Minério de Ferro e Matérias-primas, 15오 Simpósio Brasileiro de Minério de Ferro e 2ํ Simpósio Brasileiro de Aglomeração de Minério de Ferro, 15 a 18 de setembro de 2014, Belo Horizonte, MG, Brasil. 
O projeto da Manabi diferencia-se por beneficiar um ROM com conteúdo metálico inferior ao atualmente praticado no Brasil, porém com obtenção de um produto premium de alto teor de ferro e com descarte de um rejeito com conteúdo metálico inferior a prática atual de outras mineradoras.

O desenvolvimento do teste em circuito fechado de flotação surgiu da necessidade de implantar um teste em bancada para avaliação do depósito que, além de requerer pouca massa para ser executado, representasse a rota de processo escolhida devendo, principalmente, medir o desempenho da recuperação de ferro e alta qualidade do concentrado.

Testes iniciais de flotação em célula de bancada, feitos com procedimentos tradicionais, apresentaram rendimento metalúrgico bem inferior aos obtidos nos testes em escala piloto realizados pela Manabi. Isto se deve à falta de recirculação de fluxos das etapas subsequentes da flotação, razão válida para a concentração da fração grossa quanto da fração fina. Particularmente para a flotação da fração fina estas diferenças são acentuadas pelas diferentes condições hidrodinâmicas entre a célula de mecânica e as colunas de flotação previstas no projeto.

Pesquisas anteriores apontam as diferenças das partículas grossas e finas, em termos de adição especifica de reagentes e quanto a colisão e adesão de cada partícula-bolha.

Li et al [1] descreveram que os princípios básicos da flotação de partículas podem ser divididos em duas áreas principais:

i) química de superfície e;

ii) hidrodinâmica.

A química de superfície inclui:

- interações; - energia;

- adsorção em interfaces;

- molhabilidade natural dos minerais;

- uso de reagentes para tornar hidrofóbicas as superfícies minerais.

A hidrodinâmica inclui:

- dispersão das bolhas de ar;

- suspensão de sólidos na polpa;

- colisão e adesão entre partículas minerais e bolhas de ar;

- estabilidade do agregado partícula-bolha.

A flotação de finos e grossos em separado já não é novidade, principalmente nas usinas de fosfato do Brasil. As antigas Arafértil e Fosfértil já introduziram este conceito em seu processo há mais de uma década, com ganhos comprovados na recuperação de apatita, conforme Guimarães e Perez [2].

Para Itabiritos pobres, Cruz [3], comprovou ganho de 5,7\% de recuperação de ferro além de pequena redução do percentual de contaminantes quando comparada à flotação em separado de finos $(-0,044 \mathrm{~mm})$ e grossos $(-0,15 \mathrm{~mm},-0,044 \mathrm{~mm}) \mathrm{com}$ a flotação de toda a faixa granulométrica.

Uma das explicações é que finos e grossos possuem comportamento hidrodinâmico distintos, fato este comprovado por Santos [4], em experimento de marcação das fases sólida e líquida em coluna de flotação piloto conforme Figura 2x. Esta constatação é um dos fundamentos da concentração mineral que aponta maior eficiência para faixas de tamanho mais estreitas.

* Contribuição técnica ao $44^{\circ}$ Seminário de Redução de Minério de Ferro e Matérias-primas, 15오 Simpósio Brasileiro de Minério de Ferro e 2ํ Simpósio Brasileiro de Aglomeração de Minério de Ferro, 15 a 18 de setembro de 2014, Belo Horizonte, MG, Brasil. 


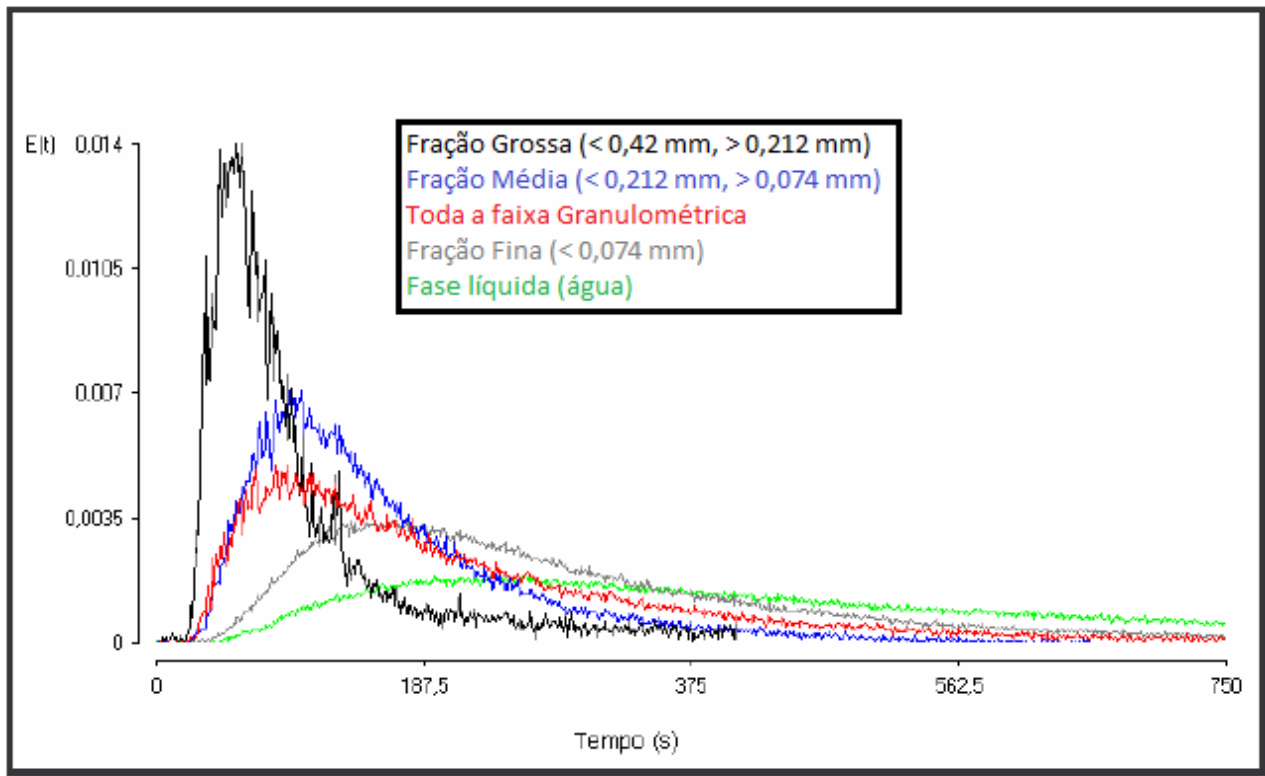

Figura 2: Curvas de distribuição de tempos de residência da água e diferentes frações granulométrica obtidas via método dos traçadores radioativos.

Os grossos apresentam tempos de residência médios menores, além de apresentar um comportamento hidrodinâmico mais próximo ao fluxo em pistão, que pode ser observado pela menor dispersão. Os finos, por sua vez, apresentam um comportamento similar ao da fase líquida, com elevados tempos de residência e grande dispersão em torno do tempo médio de residência.

Foi desenvolvido pela Manabi, em parceria com a SGS Geosol, condições diferentes de teste em bancada pela metodologia do "locked cycle test (LCT)", com as quais foi possível representar o circuito de flotação usado nos testes piloto e também previsto para o projeto e, com isto, obter teores e rendimentos metalúrgicos similares.

Durante o desenvolvimento das condições de flotação do LCT para as frações grossa e fina, foi possível comprovar que, cada fração, requer condições específicas de flotação.

\section{MATERIAIS E MÉTODOS}

As amostras utilizadas neste trabalho foram provenientes de furos de sonda realizados pela Manabi na área de pesquisa do projeto Morro do Pilar. As amostras foram selecionadas de maneira representativa de todo o corpo mineral e separadas por teores. As amostras foram também separadas em dois grupos - Pit Norte e Pit Sul - que pertencem as duas áreas a serem lavradas pela Manabi.

Foram compostas 8 amostras com aproximadamente $35 \mathrm{~kg}$ cada, com diferentes teores de ferro e diferentes localizações na jazida.

As amostras foram preparadas separadamente seguindo a etapa de britagem estagiada em $8 \mathrm{~mm}, 5 \mathrm{~mm}$ e $3,35 \mathrm{~mm}$, moagem em $0,15 \mathrm{~mm}$, sendo divididas em duas alíquotas através de peneiramento na malha de $0,053 \mathrm{~mm}$, que melhor simulou a ineficiência da futura classificação industrial em ciclones para corte em $0,044 \mathrm{~mm}$. Através do peneiramento em $0,053 \mathrm{~mm}$ foram obtidas duas frações granulométricas: o material retido na faixa $-0,15+0,053 \mathrm{~mm}$ foi denominada fração grossa e o material passante, faixa $-0,053 \mathrm{~mm}$, foi denominada fração fina, totalizando então 16 amostras testadas.

* Contribuição técnica ao 44 Seminário de Redução de Minério de Ferro e Matérias-primas, 15오 Simpósio Brasileiro de Minério de Ferro e 2ํ Simpósio Brasileiro de Aglomeração de Minério de Ferro, 15 a 18 de setembro de 2014, Belo Horizonte, MG, Brasil. 
Os testes de flotação foram realizados em célula de flotação de laboratório, modelo Denver de 2,5 litros. O tempo de condicionamento adotado para o amido foi de 5 minutos com $50 \%$ sólidos e para a amina 1 minuto com a porcentagem de sólidos já ajustada para cada fração. A dosagem de amina foi realizada de maneira fracionada durante a flotação. $\mathrm{O}$ pH utilizado foi de 10,5 para todos os testes. Diferentes parâmetros foram utilizados para a fração fina e fração grossa dos testes conforme tabela abaixo.

Tabela 1: Parâmetros de flotação para as diferentes frações granulométricas.

\begin{tabular}{cccccccccc} 
& \multicolumn{8}{c}{ Etapa } \\
\cline { 2 - 9 } & \multicolumn{2}{c}{ Rougher } & \multicolumn{2}{c}{ Cleaner } & \multicolumn{2}{c}{ Recleaner } & \multicolumn{2}{c}{ Scavenger } \\
\hline Fração & Grossos & Finos & Grossos & Finos & Grossos & Finos & Grossos & Finos \\
\hline Tempo de Flotação & 5 & 10 & 6 & 6 & 4 & 4 & 6 & 7 \\
(min) & 30 & 57 & 23 & 55 & 23 & 40 & - & 13 \\
Amina (g/t) & 30 & 40 & - & - & - & - & - & - \\
$\%$ Sólidos & 1300 & 1100 & 1300 & 1100 & 1300 & 1100 & 1300 & 1100 \\
Rotor (rpm) & 1300
\end{tabular}

A etapa rougher de todas as amostras foi realizada separadamente das demais. Foi necessária a repetição desta etapa de 8 a 9 vezes para gerar massa suficiente para as etapas subsequentes. Os concentrados obtidos foram homogeneizados $e$ quarteados em 8 a 9 alíquotas para a realização de 8 a 9 ciclos de flotação. A carga circulante gerada no primeiro ciclo (rejeito recleaner e concentrado scavenger) foram reservadas, incluindo os respectivos licores, e retornadas ao processo no ciclo seguinte. Procedeu-se dessa forma por 8 a 9 ciclos completos.

Os produtos finais de cada ciclo (rejeito scavenger e concentrado recleaner) foram coletados, secos e pesados e realizada análise química para fechamento de balanço.

A porcentagem de sólidos para as etapas cleaner, recleaner e scavenger não foram determinadas, eram consequência de cada teste. Além disso, não era acrescentado amido adcional nas etapas recleaner e scavenger

Abaixo fluxograma do locked cycle test.

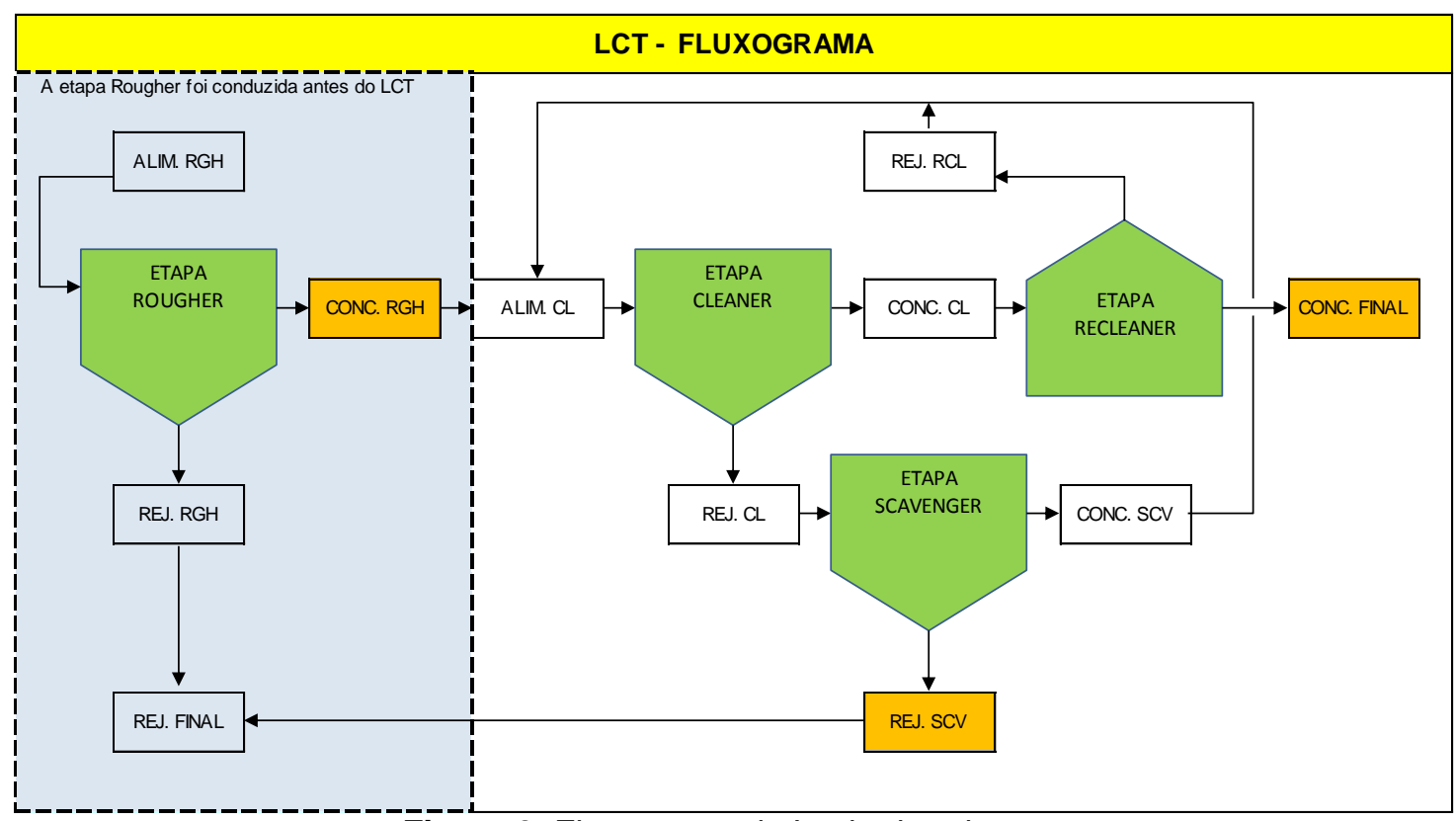

Figura 3: Fluxograma do Locked cycle test.

* Contribuição técnica ao 44은 Seminário de Redução de Minério de Ferro e Matérias-primas, 15ㅇ Simpósio Brasileiro de Minério de Ferro e 2o Simpósio Brasileiro de Aglomeração de Minério de Ferro, 15 a 18 de setembro de 2014, Belo Horizonte, MG, Brasil. 


\section{RESULTADOS E DISCUSSÃO}

\subsection{LCT- Critério de Convergência.}

O critério utilizado para verficiar a estabilidade e equilíbrio do teste foi o fechamento, para cada ciclo, do balanço de massa e metálico ( $\mathrm{Fe}$ e $\left.\mathrm{SiO}_{2}\right)$, considerando o ciclo estável quando com as entradas e saídas do sistema não apresentem diferenças. A seguir são apresentados os gráficos ilustrando a determinação do critério de convergência de alguns dos LCT's de um total de 16 realizados, sendo os 08 feitos com a fração grossa e 08 com a fração Fina.
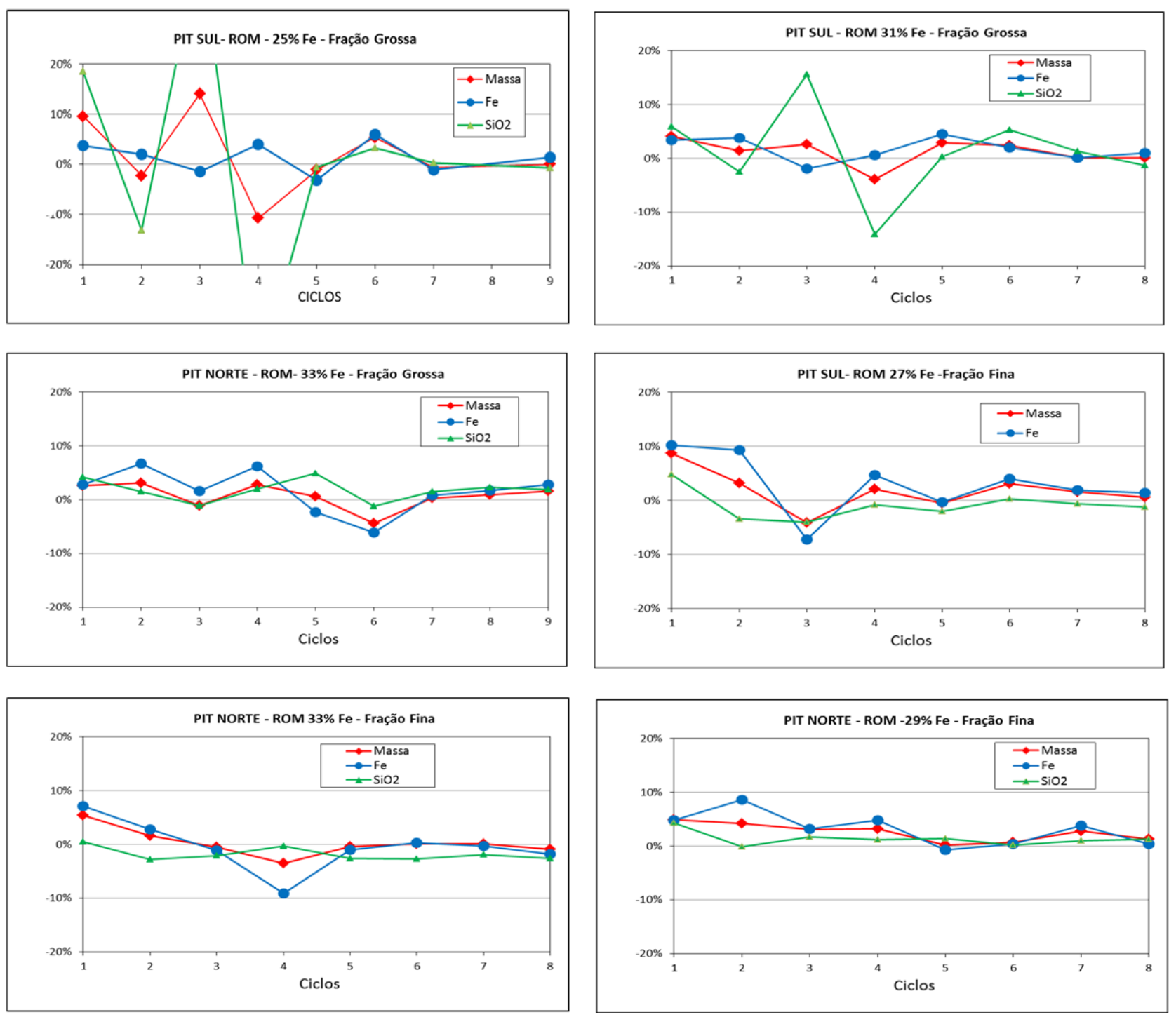

Figura 4 - Critério de convergência (Balanço de massa, Fe e SiO2 para cada ciclo do LCT)

É possível observar que nos 3 últimos ciclos o LCT entra em equilíbrio, podendo o processo ser considerado como uma operação em regime estacionário, tornando ainda mais confiáveis os resultados obtidos.

* Contribuição técnica ao 44 Seminário de Redução de Minério de Ferro e Matérias-primas, 15o Simpósio Brasileiro de Minério de Ferro e 2o Simpósio Brasileiro de Aglomeração de Minério de Ferro, 15 a 18 de setembro de 2014, Belo Horizonte, MG, Brasil. 


\subsection{Efeito do Reciclo na Recuperação do Teste}

As figuras 5 e 6 , feitos com resultados do LCT de amostras de grossos e amostras de finos ilustram bem o que acontece com a recuperação metálica ao longo das etapas de recirculação do LCT, que converge logo a partir dos 3 últimos ciclos.

Pela média móvel das recuperações metálicas (linhas pontilhadas) do LCT é possível observar que a recuperação começa no $1^{\circ}$ ciclo em um patamar mais baixo, alternando muito posteriormente entre os ciclos 2 a 5 . Lembrando que tal fato ocorre devido ao desbalanceamento metalúrgico e de massas descrito no item anterior (critério de convergência), que indica que o circuito ainda não entrou em regime.

Nos últimos 03 ciclos a recuperação tende a se manter em um determinado patamar, sempre maior que o obtido no $1^{\circ}$ ciclo do experimento, comprovando o regime do circuito.

Tal observação comprova a dificuldade de obtenção de rendimento metalúrgico similar ao obtido em regime estacionário quando o teste é feito em escala de bancada com apenas um ciclo ou etapa de flotação.

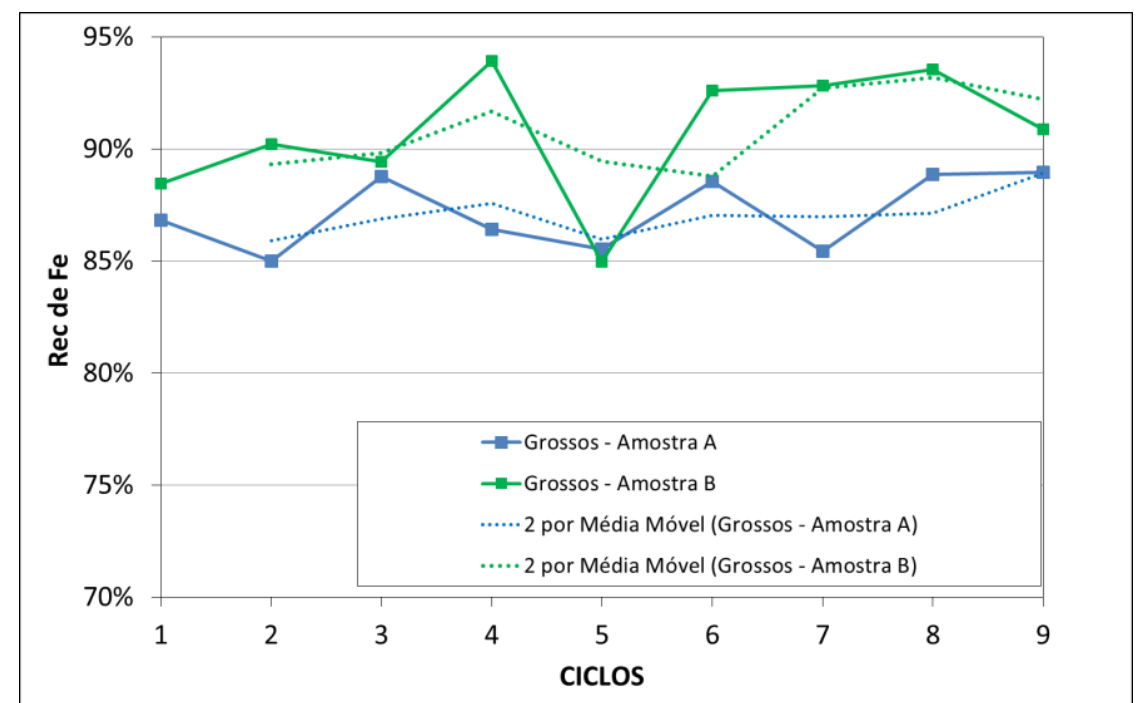

Figura 5: Efeito da recirculação aumentando a recuperação de Fe do LCT - Fração Grossa.

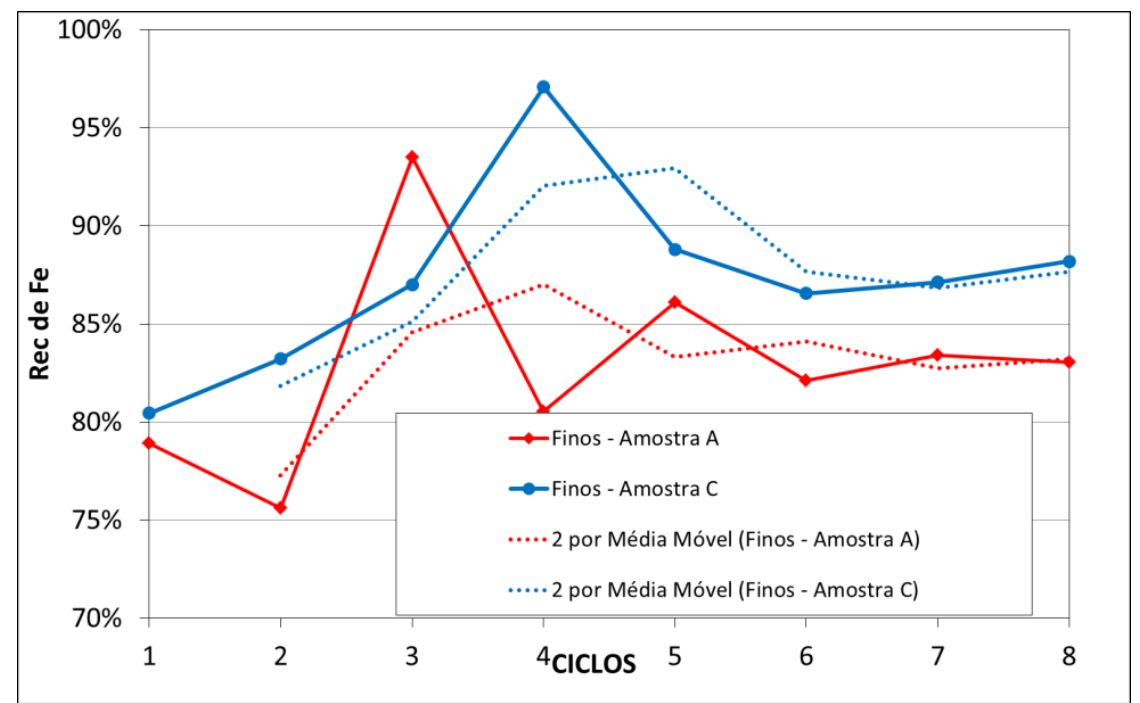

Figura 6: Efeito da recirculação aumentando a recuperação de Fe do LCT - Fração Fina.

\footnotetext{
* Contribuição técnica ao $44^{\circ}$ Seminário de Redução de Minério de Ferro e Matérias-primas, 15ํ Simpósio Brasileiro de Minério de Ferro e $2^{\circ}$ Simpósio Brasileiro de Aglomeração de Minério de Ferro, 15 a 18 de setembro de 2014, Belo Horizonte, MG, Brasil.
} 


\subsection{Resultados dos LCTs de Grossos e Finos}

As tabela 2 e 3 apresentam os resultados dos LCT's com a fração grossa e fina em separado.

Tabela 2: Resumos dos resultados obtidos com os LCTS da fração fina

\begin{tabular}{|c|c|c|c|c|c|c|}
\hline \multirow[t]{2}{*}{ PIT } & \multirow{2}{*}{$\begin{array}{l}\% \mathrm{Fe} \\
\mathrm{ROM}\end{array}$} & \multirow{2}{*}{$\begin{array}{l}\text { \% Fe Al. } \\
\text { Flotação }\end{array}$} & \multicolumn{2}{|c|}{$\begin{array}{c}\text { Concentrado } \\
\text { Final }\end{array}$} & \multirow[t]{2}{*}{$\mathrm{Rec} \mathrm{Fe}$} & \multirow{2}{*}{$\begin{array}{c}\text { Rec } \\
\text { Mássica }\end{array}$} \\
\hline & & & $\% \mathrm{Fe}$ & $\%$ Sio2 & & \\
\hline \multirow{4}{*}{ NORTE } & 28,7 & 33,4 & 68,8 & 1,6 & 87,1 & 42,3 \\
\hline & 32,1 & 33,4 & 67,2 & 2,2 & 87,6 & 41,5 \\
\hline & 32,8 & 36,1 & 68,0 & 1,7 & 86,1 & 45,7 \\
\hline & 34,9 & 36,9 & 68,5 & 1,7 & 88,3 & 47,5 \\
\hline \multirow{4}{*}{ SUL } & 25,8 & 29,6 & 67,2 & 0,6 & 78,3 & 34,5 \\
\hline & 27,5 & 30,9 & 65,9 & 2,1 & 83,9 & 39,3 \\
\hline & 28,7 & 31,1 & 69,8 & 0,7 & 80,6 & 35,9 \\
\hline & 31,1 & 33,3 & 69,7 & 0,8 & 87,6 & 41,8 \\
\hline
\end{tabular}

Tabela 3: Resumos dos resultados obtidos com os LCTS da fração grossa

\begin{tabular}{c|cc|ccc|c|c}
\hline \multirow{2}{*}{ PIT } & \multirow{2}{*}{$\begin{array}{c}\text { \% Fe } \\
\text { ROM }\end{array}$} & \multirow{2}{*}{$\begin{array}{c}\text { \% Fe Al. } \\
\text { Flotação }\end{array}$} & \multicolumn{2}{|c|}{$\begin{array}{c}\text { Concentrado } \\
\text { Final }\end{array}$} & \multirow{2}{*}{ Rec Fe } & $\begin{array}{c}\text { Rec } \\
\text { Mássica }\end{array}$ \\
\cline { 4 - 5 } NORTE & 28,7 & 26,6 & 69,3 & 0,5 & 90,0 & 34,5 \\
& 32,1 & 32,1 & 69,5 & 0,3 & 89,4 & 41,3 \\
& 32,8 & 32,8 & 69,6 & 0,3 & 92,1 & 43,4 \\
& 34,9 & 34,8 & 68,7 & 1,6 & 95,1 & 48,2 \\
\hline \multirow{4}{*}{ SUL } & 25,8 & 25,7 & 68,6 & 0,8 & 90,7 & 34,0 \\
& 27,5 & 27,1 & 68,7 & 1,0 & 94,3 & 37,2 \\
& 28,7 & 29,4 & 68,4 & 0,9 & 93,0 & 40,0 \\
& 31,1 & 32,6 & 68,6 & 0,7 & 91,8 & 43,6 \\
\hline
\end{tabular}

Todos os resultados apontam excelentes recuperações metalúrgicas com ótima qualidade obtida no concentrado final. Estes resultados só puderam ser alcançados em função das condições otimizadas anteriormente descritas para o LCT de finos e grossos.

Estes resultados estão totalmente correlacionados com os dados de uma série de testes piloto contínuo feitos pela Manabi, que apresentaram, também, excelentes recuperações metalúrgicas e altos teores de ferro nos concentrados.

\subsection{Resultados Globais dos LCTs}

A tabela 4 a seguir apresenta os resultados globais dos LCT's das 8 amostras do depósito, sendo 4 do Pit Sul e 04 do Pit Norte. O balanço de massas e metalúrgico, incluindo a deslamagem em bancada foi fechado com ajuda do Software BILMAT.

\footnotetext{
* Contribuição técnica ao $44^{\circ}$ Seminário de Redução de Minério de Ferro e Matérias-primas, 15은 Simpósio Brasileiro de Minério de Ferro e $2^{\circ}$ Simpósio Brasileiro de Aglomeração de Minério de Ferro, 15 a 18 de setembro de 2014, Belo Horizonte, MG, Brasil.
} 
Tabela 4: Resumos dos resultados obtidos com os LCTS Globais

\begin{tabular}{|c|c|c|c|c|c|c|c|c|c|c|c|c|c|}
\hline \multirow[b]{2}{*}{ PIT } & \multirow{2}{*}{$\begin{array}{l}\mathrm{Fe} \% \\
\mathrm{ROM}\end{array}$} & \multicolumn{3}{|c|}{ Lamas } & \multicolumn{3}{|c|}{ Rejeitos (grossos) } & \multicolumn{3}{|c|}{ Rejeitos (Finos) } & \multicolumn{3}{|c|}{ Concentrado Final } \\
\hline & & $\begin{array}{c}\text { Dist. } \\
\text { Mássica }\end{array}$ & $\begin{array}{l}\text { Dist. } \\
\text { Fe }\end{array}$ & $\% \mathrm{Fe}$ & $\begin{array}{l}\text { Dist. } \\
\text { Mássica }\end{array}$ & $\begin{array}{c}\text { Dist. } \\
\mathrm{Fe}\end{array}$ & $\% \mathrm{Fe}$ & $\begin{array}{c}\text { Dist. } \\
\text { Mássica }\end{array}$ & $\begin{array}{l}\text { Dist. } \\
\mathrm{Fe}\end{array}$ & $\% \mathrm{Fe}$ & $\begin{array}{l}\text { Dist. } \\
\text { Mássica }\end{array}$ & $\begin{array}{l}\text { Dist. } \\
\mathrm{Fe}\end{array}$ & $\% \mathrm{Fe}$ \\
\hline \multirow{4}{*}{ NORTE } & 28,7 & 4,7 & 1,8 & 11,1 & 35,3 & 5,0 & 4,1 & 23,8 & 6,2 & 7,5 & 36,1 & 87,0 & 69,1 \\
\hline & 32,1 & 2,6 & 0,9 & 10,6 & 32,9 & 6,1 & 5,9 & 24,2 & 7,1 & 9,4 & 40,3 & 85,9 & 68,5 \\
\hline & 32,8 & 6,4 & 2,5 & 12,6 & 31,6 & 4,4 & 4,6 & 20,5 & 5,8 & 9,2 & 41,5 & 87,4 & 69,0 \\
\hline & 34,9 & 3,4 & 1,3 & 13,1 & 29,5 & 2,8 & 3,3 & 20,8 & 4,9 & 8,3 & 46,3 & 91,0 & 68,6 \\
\hline \multirow{4}{*}{ SUL } & 25,8 & 7,8 & 2,3 & 7,7 & 34,8 & 4,9 & 3,6 & 25,9 & 9,8 & 9,8 & 31,5 & 83,0 & 68,0 \\
\hline & 27,5 & 6,5 & 2,1 & 9,0 & 32,6 & 2,9 & 2,5 & 25,2 & 7,5 & 8,2 & 35,7 & 87,4 & 67,4 \\
\hline & 28,7 & 7,0 & 2,2 & 9,2 & 31,6 & 3,8 & 3,4 & 25,8 & 8,5 & 9,4 & 35,6 & 85,5 & 68,9 \\
\hline & 31,1 & 7,8 & 2,4 & 9,7 & 29,5 & 4,5 & 4,7 & 23,1 & 5,6 & 7,5 & 39,6 & 87,5 & 68,6 \\
\hline
\end{tabular}

A figura 7 ilustra a consistência dos LCT's bem como a robustez da rota de processo escolhida pela anabiManabi. Mesmo com amostras de ROM variando entre $25 \%$ e $35 \%$ de $\mathrm{Fe}$, o processo escolhido respondeu bem e apresentou grande similaridade entre as distribuições de ferro para os diferentes fluxos da rota de processo.

Os resultados garantem também conforto e segurança quanto aos parâmetros definidos para suportar a engenharia da planta de beneficiamento industrial.

Como o minério da Manabi, não apresenta percentual considerável de "lamas", como tipicamente são conhecidos as argilas e minerais hidratados, é de se esperar que, industrialmente, isso se mostre como uma oportunidade para melhorar ainda mais a recuperação se parte desse material for enviado para as colunas. Importante também observar que, mesmo com o sucesso do desenvolvimento do teste para a fração fina, testes piloto contínuos executados pela Manabi mostram que, industrialmente, a recuperação de ferro pode ser ainda otimizada nas colunas.

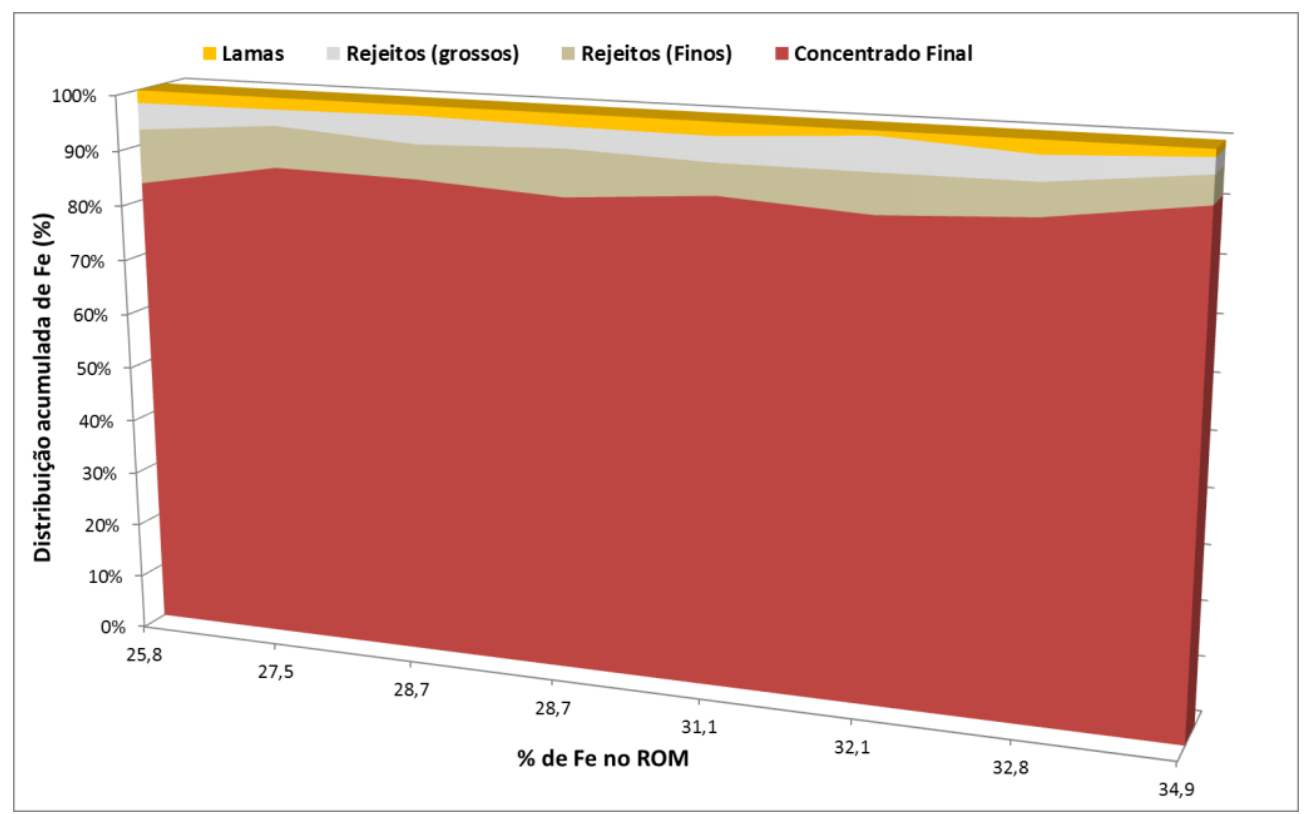

Figura 7: Similaridade dos resultados para os diferentes fluxos das diferentes amostras do LCT

\subsubsection{Qualidade dos concentrados finais obtida}

A tabela s abaixo apresenta as características químicas dos concentrados obtidos com os LCTS.

* Contribuição técnica ao $44^{\circ}$ Seminário de Redução de Minério de Ferro e Matérias-primas, 15ํ Simpósio Brasileiro de Minério de Ferro e $2^{\circ}$ Simpósio Brasileiro de Aglomeração de Minério de Ferro, 15 a 18 de setembro de 2014, Belo Horizonte, MG, Brasil. 


\begin{tabular}{|c|c|c|c|c|c|c|c|c|}
\hline \multirow{2}{*}{ PIT } & \multirow{2}{*}{$\begin{array}{l}\mathrm{Fe} \% \\
\mathrm{ROM}\end{array}$} & \multicolumn{5}{|c|}{ Concentrado Final } & \multirow{2}{*}{$\mathrm{Rec} \mathrm{Fe}$} & \multirow{2}{*}{$\begin{array}{c}\text { Rec } \\
\text { Mássica }\end{array}$} \\
\hline & & $\% \mathrm{Fe}$ & $\% \mathrm{SiO}_{2}$ & $\% \mathrm{Al}_{2} \mathrm{O} 3$ & $\% \mathbf{P}$ & LOI & & \\
\hline \multirow{4}{*}{ NORTE } & 28,7 & 69,1 & 1,1 & 0,2 & 0,012 & 0,1 & 87,0 & 36,1 \\
\hline & 32,1 & 68,5 & 1,1 & 0,2 & 0,007 & 0,1 & 85,9 & 40,3 \\
\hline & 32,8 & 69,0 & 0,9 & 0,2 & 0,007 & 0,1 & 87,4 & 41,5 \\
\hline & 34,9 & 68,6 & 1,7 & 0,2 & 0,012 & 0,4 & 91,0 & 46,3 \\
\hline \multirow{4}{*}{ SUL } & 25,8 & 68,0 & 0,7 & 0,2 & 0,026 & 0,2 & 83,0 & 31,5 \\
\hline & 27,5 & 67,4 & 1,5 & 0,5 & 0,039 & 0,8 & 87,4 & 35,7 \\
\hline & 28,7 & 68,9 & 0,8 & 0,2 & 0,046 & 0,2 & 85,5 & 35,6 \\
\hline & 31,1 & 68,6 & 0,7 & 0,2 & 0,025 & 0,1 & 87,5 & 39,6 \\
\hline
\end{tabular}

Observam-se qualidades de pellet feed premium em todos os testes realizados.

A porcentagem de $\mathrm{SiO}_{2}+\mathrm{Al}_{2} \mathrm{O}_{3}$ chegou a $2 \%$ em apenas 1 teste. A porcentagem de perda ao fogo manteve-se sempre abaixo de 1\%, enquanto a porcentagem de fósforo manteve-se dentro das especificações comuns de mercado em todos os testes.

\subsection{Correlação entre o Teor de Ferro no ROM e a Recuperação Mássica.}

A figura 8 mostra a excelente correlação obtida entre o teor de Fe no ROM e a recuperação mássica através dos resultados experimentais (LCT's).

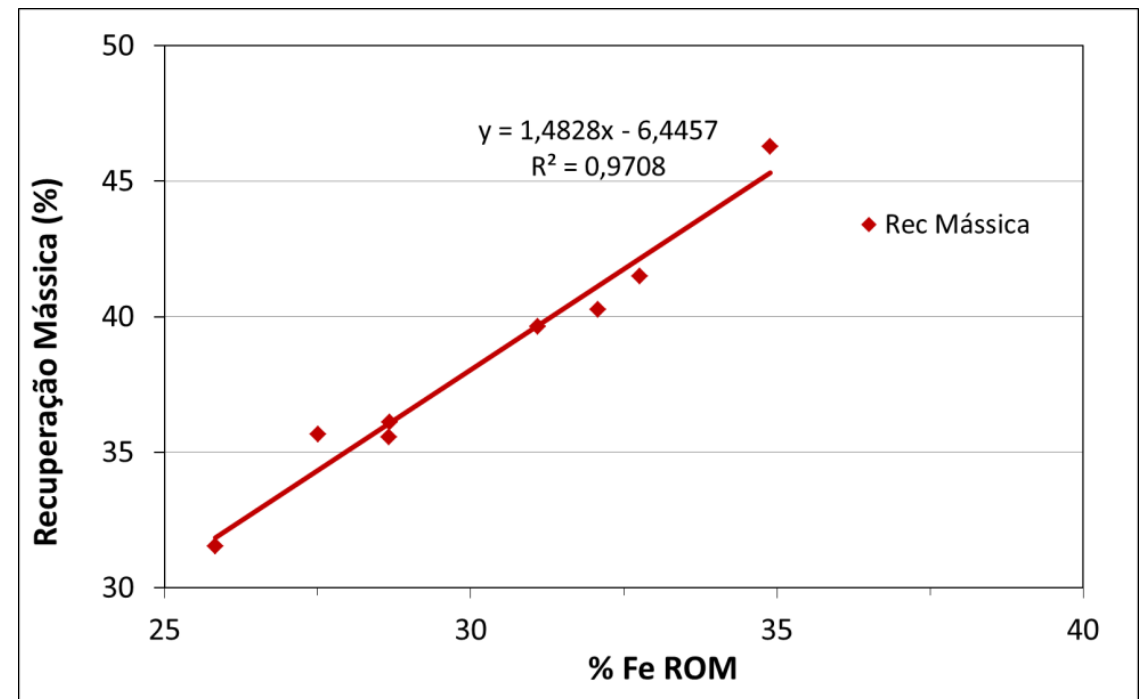

Figura 8. Correlação obtida entre o teor de $\mathrm{Fe}$ no $\mathrm{ROM}$ e a recuperação mássica através dos resultados experimentais (LCT's)

* Contribuição técnica ao 44ํㅗㄴ Seminário de Redução de Minério de Ferro e Matérias-primas, 15o Simpósio Brasileiro de Minério de Ferro e 2o Simpósio Brasileiro de Aglomeração de Minério de Ferro, 15 a 18 de setembro de 2014, Belo Horizonte, MG, Brasil. 


\section{CONCLUSÃO}

O desafio de aproveitar depósitos de minério de ferro de baixo teor vai aumentar cada vez mais a necessidade de conhecimento dos fundamentos dos processos propostos para seu beneficiamento e também a aplicação de ferramentas mais poderosas para sua avaliação.

A metodologia do locked cycle test (LCT) mostrou ser uma poderosa ferramenta para avaliação de depósitos minerais nos quais a flotação é o processo de concentração. Além de necessitar de uma massa de amostras inferior aos ensaios em escala piloto, o LCT simula muito bem o regime estacionário do processo de flotação das plantas piloto e industrial, onde ocorre a recirculação de fluxos.

A célula de flotação em bancada deve ter as suas variáveis muito bem ajustadas tais quais a porcentagem de sólidos de alimentação, rotação das células e dosagem estagiada de coletor.

O ajuste destas variáveis, de forma diferente para finos e grossos nos ensaios LCT, corrobora com a necessidade de que estas frações sejam divididas e processadas em separado, proporcionando ganhos na recuperação global do processo.

\section{Agradecimentos}

Agradecimentos a ABM pela oportunidade de publicação do trabalho e a SGS Geosol pela parceria.

\section{REFERÊNCIAS}

1 Li R, Hoberg H, Schneider FU. (1993) Investigations on the influence of particle size in flotation. In: International Mineral Processing Congress, XVIII, Sydney, 1993;3:689-697.

2 Guimarães RC, Peres AEC. (2003) Production of phosphate concentrates From slimes: Brazilian experience. Procedings XXII - IMPC. p. $606-612$.

3 Cruz MR. Flotação fracionada: aumento do rendimentoda flotação através da divisão da alimentação em duas frações granulométricas [Dissertação de Mestrado]. 2010.

4 Santos AR. Estudo do comportamento dinâmico de colunas de flotação utilizando técnicas nucleares [Dissertação de Mestrado]. 2005.

* Contribuição técnica ao $44^{\circ}$ Seminário de Redução de Minério de Ferro e Matérias-primas, $15^{\circ}$ Simpósio Brasileiro de Minério de Ferro e $2^{\circ}$ Simpósio Brasileiro de Aglomeração de Minério de Ferro, 15 a 18 de setembro de 2014, Belo Horizonte, MG, Brasil. 